\title{
ATUAÇÃO DO ENFERMEIRO INSERIDO NA EQUIPE DE REMOÇÃO DE ÓRGÃOS
}

\author{
Action of nurses in the organ removal team
}

\author{
Josely Santana do Amorim¹, Giovani Carmo da Silva², Ludmila Helena de Assis²
}

\section{RESUMO}

O processo de doação de órgãos consiste em uma conjuntura de procedimentos sistematizados que compreende a identificação do potencial doador até a realização do transplante no receptor. A remoção de órgãos sólidos é um dos procedimentos complexo no processo de doação e que exige uma equipe multiprofissional qualificada e competente para sua realização. Dentre os profissionais de saúde dessa equipe, a enfermagem participa ativamente; porém, poucos são os estudos que comprovam a real importância desse profissional inserido numa equipe de remoção. Objetivo: conhecer as funções do enfermeiro integrante da equipe de remoção de órgãos sólidos. Métodos: o percurso escolhido foi pesquisa de enfoque qualitativo e descritivo por meio da realização de entrevistas semi-estruturadas que permitiram levantar as funções, atitudes e conhecimentos de um trabalho em particular. O estudo foi realizado após aprovação do Comitê de Ética e Pesquisa da UFMG, obedecendo aos critérios de inclusão: ser enfermeiro, possuir ou não especialização na área de transplantes e ser integrante da equipe de remoção de órgãos sólidos. Resultados: este estudo teve a participação de cinco enfermeiras que se enquadravam nos critérios de inclusão. Na análise dos dados coletados, emergiram quatro categorias: responsabilidade pelo material médico-cirúrgico a ser transportado; coordenação e preparação da sala operatória no intra-operatório; avaliação e conferência da documentação do doador exigida por lei e perfusão e acondicionamento dos órgãos retirados. Discussão: Constata-se que esse enfermeiro deve ter conhecimento e domínio das atividades realizadas dentro do centro cirúrgico, desde preparação de sala operatória, tempos cirúrgicos e materiais específicos necessários para o procedimento. Essa atuação engloba a operacionalização de todo processo de remoção de cada órgão a ser retirado, além das atividades de caráter assistencial e administrativo dentro do processo de remoção de órgãos. Conclusão: evidenciou-se que o enfermeiro integrante da equipe de remoção de órgãos sólidos desta instituição atua ativamente no processo intra-operatório, que compreende atividades de caráter assistencial e gerencial dentro da sala cirúrgica.

Descritores: Enfermagem, Transplante de órgãos, Doadores de Tecidos

Instituições:

${ }^{1}$ Serviço de Transplantes do Hospital das Clínicas da Universidade Federal de Minas Gerais - Belo Horizonte, Minas Gerais, Brasil.

${ }^{2}$ Curso de Enfermagem da Universidade José do Rosário Vellano (UNIFENAS) - Belo Horizonte, Minas Gerais, Brasil.

\section{Correspondência:}

Josely Santana do Amorim

Rua Gorceix, 473 - CEP 32652-470 - Betim/MG

Tel.: (31) 3471-7040

Email: ladyenf@yahoo.com.br
Aceito em: 03.10.2011

\section{INTRODUÇÃO}

O transplante de órgãos desenvolveu-se como tratamento para doenças terminais de alguns órgãos, trazendo novo capítulo na vida do paciente, dos profissionais de saúde envolvidos e da legislação vigente no país. ${ }^{1}$ Em 1997, foi criada a lei dos transplantes que organizou o Sistema Nacional de Transplantes (SNT), estabelecendo a regulamentação e a normatização do processo de doação de órgãos por meio de trabalhos integrados às centrais estaduais, garantindo os princípios bioéticos em todas as fases executadas. ${ }^{2}$

O processo de doação e transplante é bem complexo iniciando pela identificação, notificação e manutenção dos potenciais doadores após a confirmação do diagnóstico de morte encefálica seguido da comunicação dos familiares e consentimento de doação de órgãos que serão removidos e distribuídos pela Central de Notificação e Captação de Órgãos (CNCDO). ${ }^{3}$

É importante ter uma equipe multiprofissional de captação de órgãos bem treinada para efetivamente prestar esclarecimentos aos familiares e ainda ser capaz de perceber quando a família não consegue entender o processo de doação. ${ }^{4}$

$\mathrm{O}$ enfermeiro pode participar de diversas atividades durante $\mathrm{o}$ 
processo de captação de órgãos, bem como planejar, executar, coordenar, supervisionar e avaliar os procedimentos de enfermagem prestados aos doadores de órgãos e tecidos; aos receptores cabe aplicar a Sistematização de Assistência de Enfermagem (SAE) em todas as fases do processo, que inclui o acompanhamento dos receptores no pré, intra e pós-transplante..$^{5}$

O profissional enfermeiro pode estar inserido em diversas etapas do processo de doação de órgãos, podendo notificar às CNCDOs a existência de potenciais doadores e entrevistar o responsável legal do doador. ${ }^{6}$

O enfermeiro responsável pela captação de órgãos deverá gerenciar e acompanhar as atividades realizadas durante a retirada dos órgãos no centro cirúrgico recolhendo e entregando toda documentação regularizadora à equipe de remoção de órgãos, bem como providenciar o transporte necessário dessas e dos respectivos órgãos a serem implantados. ${ }^{7}$

É responsabilidade da CNCDO comunicar e/ou acionar as equipes de remoção de órgãos para garantir a sequência do processo de doação. ${ }^{2}$ É sabido que essa equipe é composta por múltiplos profissionais, dentre eles o profissional enfermeiro. A motivação que levou a este estudo foi esclarecer qual é a atuação do enfermeiro na equipe de remoção de órgãos para transplantes, referenciando a função específica desse profissional na sala de retirada de órgãos sólidos em uma equipe específica.

Contudo, esse esclarecimento vem pormenorizar as dúvidas acadêmicas, cientificas e da sociedade referentes às funções específicas do enfermeiro em uma das etapas do processo de doação de órgãos. Considerando a falta de conteúdo embasado no conhecimento científico a respeito da atuação do enfermeiro durante o processo de retirada de órgãos, é justificada e propiciada a oportunidade de buscar o enriquecimento sobre o assunto.

\section{MÉTODO}

A presente pesquisa trata de uma análise qualitativa e descritiva realizada no Hospital das Clínicas da Universidade Federal de inas Gerais - UFMG, considerado centro de referência em transplantes da região metropolitana de Minas Gerais.

A pesquisa foi realizada no período compreendido entre novembro de 2010 e junho de 2011; a amostra foi do tipo intencional, onde foram realizadas entrevistas com enfermeiras que atuam como integrantes da equipe de remoção de órgãos sólidos da instituição. Para realização da pesquisa, foram considerados critérios de inclusão e exclusão propostos pelos pesquisadores, que nortearam a escolha dos enfermeiros a serem entrevistados.

Os critérios de inclusão definidos pela pesquisa foram: enfermeiros que trabalham atualmente em equipes de remoção de órgãos, que possuem título de especialista ou não em transplante e que atuam em equipes de remoção de órgãos sólidos. Sendo assim, foram entrevistadas cinco enfermeiras que se enquadravam dentro do perfil escolhido.

O processo de coleta de dados foi realizado através de uma entrevista semi-estruturada previamente elaborada com onze questões abertas, que orientou o pensamento e descrição das enfermeiras, deixando-as falar livremente, não sendo determinado o tempo de duração de cada entrevista. Isso favoreceu o alcance, a liberdade e a espontaneidade necessários das entrevistadas, enriquecendo a investigação.
As entrevistas foram realizadas após o consentimento, e o agendamento com as enfermeiras ocorreu dentro da instituição em que elas trabalham, e, respectivamente, em seu setor de atuação. A concessão das entrevistas ocorreu após aprovação do Comitê de Ética de Pesquisa da Universidade Federal de Minas Gerais (COEP) por meio do parecer $n^{\circ}$ ETIC 0553.0.203.000-10 e após leitura e assinatura das enfermeiras do Termo de Consentimento e Livre Esclarecido (TCLE). Motivadas pela proposta de sigilo de identidade garantida pelos pesquisadores, as entrevistadas foram identificadas aleatoriamente na pesquisa em questão por letras em ordem alfabética (A, B, C, D e E).

A análise dos dados foi realizada através da técnica de análise temática de conteúdo proposta por Minayo, ${ }^{8}$ que ocorreu em três momentos a fim de facilitar o entendimento da técnica e manter uma forma contínua e dinâmica. No primeiro momento, na préanálise, em que as entrevistas foram gravadas e transcritas pelos pesquisadores organizando o material coletado e, posteriormente, lendo e demarcando por aproximação do sentido geral dos discursos. No segundo momento, houve a exploração do material seguida da classificação dos dados, de acordo com as funções exercidas pelo profissional enfermeiro, dividindo-se em: atividade assistencial e atividade administrativa. No terceiro momento, o tratamento dos resultados e a interpretação dos dados foram relacionados com as evidências científicas do processo.

\section{RESULTADOS}

Quanto ao perfil das entrevistadas participantes do estudo, evidenciou-se em cinco enfermeiras integrantes da equipe de remoção de órgãos do Hospital das Clínicas da UFMG, sendo que dentre elas, somente três são especialistas em Enfermagem Hospitalar na área de Transplantes. O sexo feminino foi predominante nessa amostra e a faixa etária variou de 29 a 50 anos. Além de integrarem a equipe de remoção de órgãos da instituição, essas enfermeiras também atuam em áreas distintas dentro da instituição, sendo que três enfermeiras atuam no Ambulatório Bias Fortes anexo ao Hospital das Clínicas da UFMG, que se destina ao atendimento de pacientes na fila de espera de transplantes e pacientes pós-transplantados, e duas enfermeiras atuam no Centro Cirúrgico do Hospital das Clínicas da UFMG, que se destina ao atendimento de pacientes no intra-operatório de transplantes.

A análise dos dados coletados pelas entrevistadas evidenciou 0 agrupamento das categorias iniciais por semelhança de informações que resultaram em duas categorias dentro do processo de remoção de órgãos: 1) atividades de caráter assistencial exercidas pelo enfermeiro e, 2) atividades de caráter administrativo exercidas pelo enfermeiro.

Indiferentemente ao trabalho que as enfermeiras executam no centro cirúrgico ou no ambulatório, dentro da equipe de remoção elas exercem as mesmas atividades, não descuidando dos aspectos gerenciais condizentes com ações de planejamento, organização e implementação da assistência. Após análise da categorização inicial reagrupou-se as semelhanças, o que resultou em quatro categorias finais emergidas no estudo, apresentadas a seguir.

CATEGORIA 1: Responsabilidade pelo material médicocirúrgico a ser transportado

Quando a equipe recebe a comunicação da CNCDO para a realização da remoção de órgãos sólidos em doador falecido, ${ }^{9}$ inicia-se uma operacionalização para continuidade de todo processo, sendo 
necessário que o enfermeiro faça a separação do material médicocirúrgico e da solução de preservação que serão utilizados com o intuito de manter a viabilidade dos órgãos retirados.

Segundo os discursos das enfermeiras C e E, o enfermeiro é responsável pelo material médico-cirúrgico a ser transportado para o local onde será realizada a cirurgia de extirpação dos órgãos doados; esses materiais serão utilizados durante o procedimento dentro do centro cirúrgico.

Enfermeira C: “[...] A gente leva a mala com materiais cirúrgicos e as caixas com gelo para colocar o órgão; é nossa responsabilidade o transporte desse material, além de organizar toda a dinâmica do trabalho em sala cirúrgica, checando todo material, se a sala está com tudo ok".

Enfermeira E: “[...] O plantão médico do hospital aciona a enfermeira, que fica responsável por providenciar o contêiner com gelo estéril e não-estéril mais a mala com os materiais médicocirúrgicos que ficam dentro da farmácia-satélite do centro cirúrgico que vai ser transportado junto com a equipe de remoção."

CATEGORIA 2: Coordenação e preparação da sala operatória no intra-operatório

O estudo aponta a responsabilidade do enfermeiro enquanto coordenador e supervisor dentro da sala cirúrgica onde acontece a cirurgia do doador; essa atividade inclui a instrução e verificação da montagem da sala cirúrgica, juntamente com a circulante da sala. A enfermeira $\mathrm{C}$ destaca essa responsabilidade de organização da sala cirúrgica antes do início do procedimento.

Enfermeira C: "[...] A gente organiza toda a dinâmica do trabalho na sala cirúrgica, checando todo material, se a sala está com tudo ok. Montagem dos materiais necessários para perfusão do órgão.”

Enfermeira A: “[...] todas as anotações quem faz é o enfermeiro durante o perioperatório. Conferimos a montagem da sala junto com o circulante da sala, a gente sempre passa a relação do instrumental que vai ser utilizado, além de materiais específicos como martelo estéril, bacias, suportes de soro que devem ser bem altos e fortes, coisas assim..."

Enfermeira C: "[...] É função da enfermeira orientar e conferir a montagem da sala cirúrgica para a retirada; também somos nós que anotamos os horários do procedimento cirúrgico, principalmente o momento da clampagem e da perfusão do órgão."

CATEGORIA 3: Avaliação e conferência da documentação do doador exigida por lei

Em relação à conferência da documentação, segundo as enfermeiras $\mathrm{C}$ e E deve ser dispensada atenção especial ao protocolo de doação da CNCDO. Consiste da existência dos impressos do Termo de Consentimento de Doação assinado pela família e do Protocolo de Morte Encefálica, confirmado e assinado pelos médicos, que são anexados ao prontuário do doador. Esses documentos são de suma importância e exigidos pela legislação brasileira. ${ }^{2}$

Enfermeira C: "[...] antes do início da cirurgia, a gente confere a existência do protocolo de morte encefálica e o termo de doação assinado pela família; isso já foi problema, quando o prontuário não vinha junto com o doador no transporte; agora, o MG Transplante sempre manda uma cópia para cada equipe de remoção. Ficou bem mais fácil a conferência, que continua sendo feita na sala cirúrgica."

Enfermeira E: “[...] a gente chega lá e verifica a documentação, se o protocolo de doação não está completo nem tem a retirada..."
CATEGORIA 4: Perfusão e acondicionamento dos órgãos retirados

O estudo mostra que as enfermeiras da equipe de remoção de órgãos da instituição estudada são responsáveis pela montagem do sistema de infusão da solução de preservação, como também pela administração e controle do tempo de infusão dessa solução, informação confirmada pelos relatos das enfermeiras B, A e C.

Enfermeira B: "[...] Somos nós responsáveis pela solução, acondicionamento, pelo ato da perfusão do órgão e também pelo acondicionamento deste depois da retirada..."

Enfermeira A: “[...] Também na parte da perfusão, exclusivamente, manter a solução em condição ideal para fazer a perfusão em condições ideais, porque tudo isso vai comprometer esse órgão. [...] por falta de gelo, por exemplo, você vai perder o órgão, vai inativar um órgão que foi retirado, por essa falta ou pelo acondicionamento inadequado, pela perfusão inadequada."

Enfermeira C: “[...] a montagem dos materiais necessários para perfusão do órgão na sala do doador é de responsabilidade da enfermeira."

\section{DISCUSSÃO}

Em relação à responsabilidade pelos materiais médico-cirúrgicos a serem transportados pela equipe de remoção de órgãos durante o procedimento cirúrgico de remoção de órgãos, observa-se que cada órgão tem características distintas, necessita de instrumentais cirúrgicos específicos, bem como da utilização de soluções fisiológicas e soluções de perfusão e preservação diferentes a $4^{\circ} \mathrm{C}$ para a criopreservação. ${ }^{10}$

Fica explícita a necessidade do profissional enfermeiro ter domínio do centro cirúrgico para viabilizar a organização dos materiais utilizados durante o trans-operatório da remoção de órgãos, fator esse que poderá ser decisivo para o sucesso da cirurgia.

A sala de cirurgia do doador é preparada para um procedimento maior de laparotomia; a montagem dessa sala consiste em instrumentos cirúrgicos básicos de laparotomia, instrumentos cardiovasculares, serra esternal elétrica e instrumentos de nefrectomia. A mesa de instrumentos de tamanho médio, coberta e estéril é necessária para a preparação e perfusão dos órgãos longe do campo operatório estéril principal e das mesas de instrumentação. ${ }^{11}$

No que diz respeito à coordenação e preparação da sala operatória no intra-operatório, durante os procedimentos anestésicos cirúrgicos dentro do centro cirúrgico, o profissional enfermeiro tem função de destaque na equipe multiprofissional porque, juntamente com o anestesista, tem como atribuição o planejamento e a organização de todo o material necessário para a realização do procedimento. ${ }^{12}$ O enfermeiro deve ter conhecimento de todo material a ser utilizado, bem como da montagem adequada da sala cirúrgica, pensando também na perfusão do órgão ex situ naquele local. ${ }^{13}$ Segundo os relatos das enfermeiras $\mathrm{A}$ e $\mathrm{D}$, existem materiais específicos que devem ser solicitados à circulante de sala e que contribuirão para o bom andamento da cirurgia. As anotações intra-operatórias são de importância vital para legitimação do processo de doação e obediência do tempo de isquemia fria de cada órgão.

A função gerencial do enfermeiro não está mais restrita ao ato operatório. Pode-se identificar nesse profissional, principalmente, a função de coordenador, cuja presença é de extrema importância para o total sucesso do transplante. ${ }^{12}$ 
A avaliação e conferência da documentação do doador exigida por lei é algo imprescindível. Assim, embora algumas atividades não sejam de competência da enfermeira, ela é co-responsável por sua realização; por isso, a conferência desse protocolo é imprescindível para que não haja erros no processo. ${ }^{14}$

Outro fator importante apontado no estudo é a perfusão fria e o acondicionamento dos órgãos retirados. A perfusão e oarmazenamento hipotérmico são realizados com uma solução de hiperosmolaridade relativa contendo solutos impermeabilizantes como citrato, sulfato, fosfato, glicose ou manitol, magnésio e quantidades variadas de sódio e potássio. Essa perfusão e armazenamento adequados são necessários para garantir o tempo de isquemia fria do órgão e possibilitar uma cirurgia de transplante viável. ${ }^{13-15}$

Esse processo de preservação confere grandes vantagens ao programa de transplante, como o tempo para transportar o órgão do hospital doador para o hospital receptor, tempo para permitir que seja realizada a equivalência tecidual para órgãos nos quais essa equivalência é importante e tempo para preparar adequadamente o receptor e a equipe cirúrgica e qualidade da função do órgão, que torna a evolução pós-operatória mais tranquila. ${ }^{13}$

\section{CONCLUSÃO}

Evidenciou-se que o enfermeiro integrante da equipe de remoção de órgãos sólidos desta instituição atua ativamente no processo intra-operatório desse procedimento, que compreende atividades de caráter assistencial e gerencial dentro da sala cirúrgica.

Sendo assim, é imprescindível que o enfermeiro integrante dessa equipe tenha conhecimento do centro cirúrgico, além de toda operacionalização dinâmica de preparação, perfusão, remoção, acondicionamento e transporte, que caracteriza o processo de remoção de órgãos sólidos.

\section{ABSTRACT:}

The organ donation process poses a set of systematic procedures including identification of potential donor until the transplantation is performed in the receiver. The removal of solid organs is one of the complex donation processes and requires a qualified and competent multidisciplinary team to perform it. Among the health professional team, nursing has an active role, but there are few studies demonstrating the real importance of this professional inserted in the organ removal. : To know the functions of the nursing member within the solid organ removal team. Method: It was chosen the qualitative and descriptive research by conducting interviews that allowed us to survey the roles, attitudes and knowledge of a particular function. The study was conducted after approved by the Ethics and Research Committee of UFMG, according to the following criteria for inclusion: being a nurse with or without expertise in the transplantation area, and being a member of a solid organ removal team. Results: The study was attended by five nurses that fulfilled the inclusion criteria. In the data analysis, four categories emerged: responsibility by medical and surgical equipment to be transported; coordination and preparation of the operating room along the surgery, assessment and checking of the donor's documentation required by law, and the organs perfusion and packaging of removed organs. Discussion: This confirms that nurses must have knowledge and control activities carried out within the surgical room by providing the preparation of the operating room, surgical and specific materials necessary for the procedure. This activity includes working in the whole removal process of each organ, added to activities of administrative and assistance feature in the organ removal process.

Conclusion: It was evident that the nursing member of the solid organs removal team is active in this institution in the intra-operative process that includes caring and management activities within the surgical room.

Keywords: Nursing, Organ Transplantation, Tissue donors

\section{REFERÊNCIAS:}

1. Garcia VD. A política de transplantes no Brasil. Revista da AMRIGS. 2006;50(4):313-20.

2. Ministério da Saúde (BR). Lei 9434. 4 de fevereiro de 1997. Dispõe sobre a remoção de órgãos, tecidos e partes do corpo humano para fins de transplantes e tratamentos e da outras providências. Disponível em: http:// www.planalto.gov.br/ccivil_03/Leis/L9434.htm.

3. Moraes EL, Massarollo MCKB. A recusa familiar para a doação de órgãos e tecidos para transplante. Rev. Latino-Am. Enfermagem. 2008; 16(3): 45864.

4. Silveira PVP, Silva AA, Oliveira ACS, Alves AJ, Quaresemin CR, Moraes $\mathrm{C}$, Et al. Aspectos éticos da legislação de transplante e doação de órgãos no Brasil. Revista Bioética. 2009;17(1):61-75.

5. Conselho Federal de Enfermagem. Resolução COFEN 292, de 07 de junho de 2004. Normatiza a atuação do enfermeiro na captação e transplante de órgãos e tecidos. Disponível em http://www.portalcofen.gov.br/2007/ materias.asp?ArticleID=7120\&sectionID=34.

6. Cicolo EA, Roza BA, Schimer J. Doação e transplantes de órgãos: produção cientifica da enfermagem brasileira. Rev Bras Enferm. 2010;63(2):274-8.

7. Roza BA, Efeitos do processo de doação de órgãos e tecidos em familiares: Intencionalidade de uma nova doação [tese]. São Paulo: Universidade Federal de São Paulo; 2005.
8. Minayo MCS. O desafio do conhecimento: pesquisa qualitativa em saúde. São Paulo: Hucitec; 2008.

9. Ministério da Saúde (BR). Portaria n².600, de 21 de outubro de 2009. Aprova o Regulamento Técnico do Sistema Nacional de Transplantes. Disponível em: http://www.brasilsus.com.br/legislacoes/gm/101249-2600. html?q=

10. Pereira WA, Fernandes RC, Soler WV. I Reunião de diretrizes básicas para captação e retirada de múltiplos órgãos e tecidos da Associação Brasileira de Transplantes de Órgãos. São Paulo: ABTO; 2003.

11. Rothrock JC. Alexander - Cuidados de Enfermagem ao paciente cirúrgico. Rio de Janeiro: Elsevier; 2007.

12. Cintra V, Sanna MC. Transformações na administração em enfermagem no suporte aos transplantes no Brasil. Rev Bras Enferm. 2005; 58(1): 78-81.

13. Ferro LAR, Ribeiro ER. Princípios básicos para conservação de órgãos para transplante. Rev Inspirar. 2009;1(1):25-28.

14. Dalri MCB, Rossi LA, Carvalho EC. Aspectos éticos e legais das anotações de enfermagem nos procedimentos de doação de órgãos para transplantes. Rev Escola Enferm da USP. 1999;33(3):224-30.

15. Correia E. Solução para conservação de órgãos: princípios básicos. Rev O.F.I.L. 2002. 